It is well known from wireless telegraphy that sunlight ionises very strongly the higher atmosphere, and it may be that the accumulated ionising effect of the sunlight and of the electric rays illuminates the atmosphere to a greater altitude than the electric rays alone. Perhaps also the ionisation lifts up the atmosphere by electric charge, as in Vegard's theory, or perhaps such a lifting up may be the effect of a raising of the temperature in those regions. A detailed study of photographs of the spectra of these high rays may solve the question as to the cause of this effect of sunlight on the altitude of the aurora.

Oslo, Norway. Cart Stromer.

\section{The Existence of more than one Ionised Layer} in the Upper Atmosphere.

DURING the past year and a half systematic observations have been made at this station on the characteristics of wireless waves deviated by the upper atmosphere. These observations, which have been made as part of the programme of the Radio Research Board of the Department of Scientific and Industrial Research, were begun in collaboration with Mr. M. A. F. Barnett and have more recently been continued with Mr. J. A. Rateliffe's assistance.

As part of such routine measurements many determinations of the equivalent height of the Kennelly-Heaviside layer have been made, utilising special transmissions from the National Physical Laboratory and from the stations of the British Broadcasting Company. The early summer observations of 1926 showed that the night-time height of this deviating layer, for wave-lengths of 400 metres, was usually $90 \mathrm{~km}$. to $130 \mathrm{~km}$. During the period October 1926-May 1927, however, heights of an entirely different order of magnitude, namely $250 \mathrm{~km}$. to $350 \mathrm{~km}$., have been frequently measured during the three hours before dawn. On such occasions, after the high values have been recorded for two or three hours, a discontinuity in the series of values occurs 30 to 40 minutes before sunrise, and heights of the normal value are again recorded.

The experimental evidence, the detailed discussion of which will appear shortly, leaves little doubt that on such occasions, in the period before dawn, the ionisation in the Kennelly-Heaviside layer has been sufficiently reduced by recombination to permit of its penetration by waves of this frequency. Reflection, however, takes place at an upper layer which is richer in ionisation. With the advent of sunrise at a height of $100 \mathrm{~km}$. or so, the Kennelly-Heaviside layer is formed again and deviation by the lower layer is suddenly established, the normal fall of the under boundary of tho latter proceeding afterwards as the more direct solar influence increases the region ionised. As the day further proceeds, the experimental results suggest that another region of ionisation is formed below the Kennelly-Heaviside layer, which, while causing attenuation of the waves, does not very materially affect the height at which they are deviated.

The obvious bearing of these results on the nature of the solar radiation responsible for atmospheric ionisation and their correlation with the results of terrestrial magnetism must await a more detailed discussion. 'There is, however, one small point which may be mentioned here. It seems of interest in indicating the possibility that simultaneous observations between the same two stations on widely different wave-lengths might enable us to study the characteristics of both layer's at the same time. Since ultrashort waves require a greater electron concentration to deflect them back than do the longer waves, there may not be enough electrons in the Kennelly-Heaviside layer to send back the former, so that for angles of incidence less than a certain amount $(e . g$. in short distance transmission), such wave-lengths would be deviated by the upper layer at all times of the day. The relatively large amplitude of the ray returned from the upper layer in the experiments mentioned above, in which 400 motro waves were used, demonstrates the low attenuation consequent on deviation at such great heights, so that with ultra-short waves the greater part of the absorption would probably take place in the penetration of the lower layer. Thus, even for transmission over long distances, we might expect a higher ray path, and deviation at the upper layer would result in less resultant absorption than a low ray path with deviation at the Kennelly-Heaviside layer. It may be mentioned in this connexion that the American determinations of the height at which these ultra-short waves are 'reflected' fit in with the above ideas of their deviation at the upper layer.

Radio Research Station,

E. V. ApPleton.

Dogsthorpe,

Peterborough.

Barrier Reefs of Tahiti and Moorea.

Tre surprising fact that fragments of volcanic rock occur in the barrier reef of Tahiti, as reported by Dr. Crossland in Natuke for April 23, must be welcomed by all students of that remarkable structure; but that fact does not, it seems to me, prove the "original continuity of the present barrier reef from the [island] shore to the ocean slope" outside the reef, as is stated in his second letter in the issue of July 2. The fact only permits the inference that the lagoon was formerly filled in some manner, perhaps by stream deltas instead of by a broadened fringing reef, so that island detritus could be transported to where the barrier now stands. This inference involves so extraordinary a series of changes from former lagoon filling to later lagoon excavation - for which there is no other satisfying evidence provided-that even the inference should not be accepted as valid until all other possible means of explaining the occurrence of the volcanic fragments have been excluded. Further details as to the naturo of the fragments and the manner of their occurrence are desirable.

Dr. Crossland's rejection of the physiographio evidence for the subsidence of Tahiti, as provided by drowned-valley bays and as given in my account of the island (Annales de Géographie, 27, 24l-284; 1918), seems to me of a piece with the neglect of such evidence on the part of Murray, Guppy, A. Agassiz, and other students of coral reefs ; and that neglect was clearly the result of their unfarniliarity with physiographic evidence rather than of its weakness. Regarding the occurrence of embayed valleys, my observations in 1914 led me to be just as positive in asserting their presence near the isthmus which connects the two cones of the Tahiti doublet as Dr. Crossland is in asserting that "There are no bays in Tahiti." The bays to which I refer are "little bays which," as Dr. Crossland says, "open out of Port Phæton,". and inasmuch as they enter well back of the goneral shore line of the island between eroded slopes of volcanic rock, I took them to be the partly drowned valleys of ordinary streams, and so still regard them, in spite of their being described as "peculiar" by Dr. Crossland and as "certainly not drowned valleys." But I fully agree that Port Phæton Bay is merely a re-entrant space between the two confluent volcanoes of which Tahiti is composed. This origin was by no means overlooked in my article, for I there said that Port Phweton Bay on the south- 